\title{
Bacterial translocation and mortality on rat model of intestinal ischemia and obstruction ${ }^{1}$
}

\author{
Rafael Izar Domingues da Costa', Roberto Rasslan", Marcia Kiyomi Koike"', Edivaldo Massazo Utiyama'v, \\ Edna Frasson de Souza Monterov \\ 'Fellow PhD degree, Postgraduate Program in Surgical Clinics, Department of Surgery, Faculdade de Medicina da \\ Universidade de Sao Paulo (FMUSP), Brazil. Acquisition, analysis and interpretation of data; technical procedures; \\ manuscript preparation. \\ "PhD, Division of General Surgery and Trauma, LIM-62, Department of Surgery, FMUSP, Sao Paulo, Brazil. Acquisition, \\ analysis and interpretation of data; technical procedures; manuscript preparation. \\ IIIPhD, Laboratory of Emergency Medicine - LIM-51, Department of Surgery, FMUSP, Sao Paulo, Brazil. Analysis and \\ interpretation of data, statistical analysis, manuscript writing. \\ IVPhD, Full Professor, Division of General Surgery and Trauma, LIM-62, Department of Surgery, FMUSP, Sao Paulo-SP, \\ Brazil. Scientific and intellectual content of the study, final approval. \\ VPhD, Associate Professor, Laboratory of Surgical Physiopathology, LIM-62, Department of Surgery, FMUSP, Sao Paulo-SP, \\ Brazil. Conception and design of the study, critical revision, final approval.
}

\section{Abstract}

Purpose: To develop an experimental model of intestinal ischemia and obstruction followed by surgical resection of the damaged segment and reestablishment of intestinal transit, looking at bacterial translocation and survival.

Methods: After anesthesia, Wistar rats was subject to laparotomy, intestinal ischemia and obstruction through an ileal ligature $1.5 \mathrm{~cm}$ of ileum cecal valve; and the mesenteric vessels that irrigate upstream of the obstruction site to approximately 7 to $10 \mathrm{~cm}$ were ligated. Abdominal wall was closed. Three, six or twenty-four hours after, rats were subject to enterectomy followed by an end to end anastomosis. After $24 \mathrm{~h}$, mesenteric lymph nodes, liver, spleen and lung tissues were surgically removed. It was studied survival rate and bacterial translocation. GraphPadPrism statistical program was used.

Results: Animals with intestinal ischemia and obstruction for 3 hours survived 24 hours after enterectomy; $6 \mathrm{~h} \times 24 \mathrm{~h}$ : survival was $70 \%$ at 24 hours; $24 \mathrm{~h} \times 24 \mathrm{~h}$ : survival was $70 \%$ and $40 \%$, before and after enterectomy, respectively. Culture of tissues showed positivity on the $6 \mathrm{~h} \times 24 \mathrm{~h}$ and negativity on the $3 \mathrm{~h} \times 24 \mathrm{~h}$.

Conclusion: The model that best approached the clinic was the one of $6 \times 24 \mathrm{~h}$ of ischemia and intestinal obstruction, in which it was observed bacterial translocation and low mortality rate. Key words: Bacterial Translocation. Mesenteric Ischemia. Intestinal Obstruction. Survival 


\section{Introduction}

Intestinal obstruction accounts for $20 \%$ of all hospitalizations due to abdominal pain $^{1}$, with a subsequent mortality of 30.000 people per year in the United States ${ }^{2}$. The physiopathology of intestinal obstruction includes increase intra-luminal pressure, edema on affected intestine segment and venous congestion, which may lead to necrosis in cases where the blood supply is severely compromised $^{3}$.

The experimental model in rats established to reproduce intestinal obstruction consists of the terminal ileum ligation, approximately $1 \mathrm{~cm}$ from the ileo-cecal valve, as described by Mulvihill et al. ${ }^{4}$, and reproduced in other studies ${ }^{5,6}$. As consequence, bacterial translocation and systemic inflammatory occur $^{7-9}$.

Zanoni et al. ${ }^{10}$ proposed a model modification, adding ischemia to intestinal obstruction, by ligature of terminal ileum blood vessels (7 to $10 \mathrm{~cm}$ of extension), promoting bacterial translocation and inflammatory response.

In humans, enterectomy of damaged intestinal segment followed by anastomosis is recommended as a surgical treatment ${ }^{11}$. Rasslan et al. ${ }^{12}$ performed enterectomy and anastomosis 24 hours after induction of intestinal ischemia and obstruction in an experimental model. An important difference from other models is that was performed an intestinal obstruction in closed loop. After 24-hour, period, surely induced a systemic inflammatory response. However, a temporal analysis after enterectomy and sample collection pointed to a gap of details of bacterial translocation. The aim of this study was develop an experimental model of intestinal ischemia and obstruction followed by surgical resection of the damaged segment and reestablishment of intestinal transit, looking at bacterial translocation and survival.

\section{Methods}

This study was approved by the Research Ethics Committee of the Faculdade de Medicina, Universidade de São Paulo (Process number 429/13), and the experiments were performed according the International guidelines for the care and use of laboratory animals.

Male Wistar rats (250-300 g) were purchased from the Department of Laboratory Animal Science of the Faculdade de Medicina, Universidade de São Paulo and were kept under a 12-h light/dark cycle at a controlled temperature $\left(23^{\circ} \mathrm{C}\right)$ room, with free access to food and tap water one week before the experiments.

It was developed three different experimental protocols applied to establish duration of intestinal ischemia and obstruction to promote bacterial translocation (Figure 1). Ten rats per protocol were submitted to experiments.

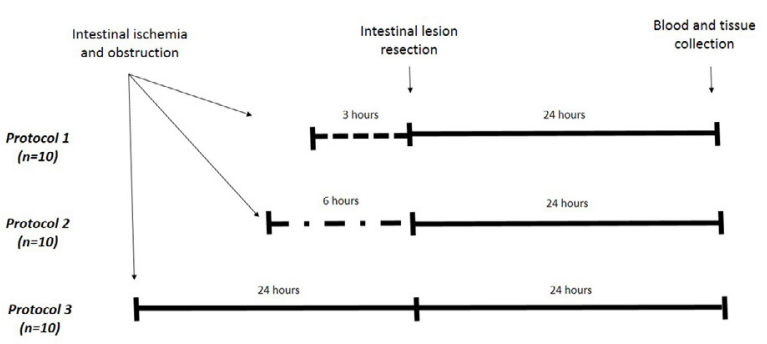

Figure 1 - Three distinct experimental protocol of intestinal ischemia and obstruction. All protocols use same surgical procedures and blood and tissue collection. The difference consists in time intervals between intestinal ischemia and obstruction and surgical resection of the intestinal lesion. 
Intestinal ischemia and obstruction surgical procedure

The animals received a mixture of ketamine and xylazine $(60 \mathrm{mg} / \mathrm{kg}$ and $10 \mathrm{mg} / \mathrm{kg}$, respectively, i.m.) to anesthesia and half of the initial dose to complement during procedure. For postoperative analgesia, animals received Tramadol (5 mg/kg, i.m., each $12 \mathrm{~h}$ ). The protocol of intestinal ischemia and obstruction used was adapted from a previously described excluding the second ligature of the intestine ${ }^{12}$.

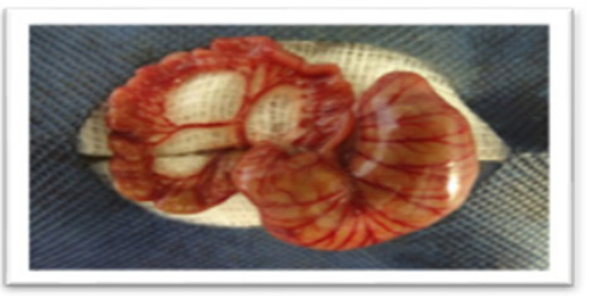

Briefly, after asepsis, a small $(3 \mathrm{~cm})$ laparotomy was performed to expose the cecum and terminal ileum. To promote intestinal ischemia and obstruction, it was done an ileal ligature $1.5 \mathrm{~cm}$ of ileum cecal valve; and the mesenteric vessels that irrigate upstream of the obstruction site to approximately 7 to $10 \mathrm{~cm}$ were ligated (Figure 2).

The abdominal wall was sutured with Nylon 4.0 and the animal return to individual cage with free access to water.

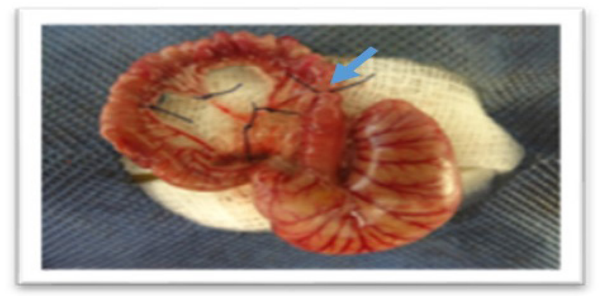

Figure 2 - Photography of rat small bowel showing terminal ileum, cecum and the vascular supply of the mesentery (left panel) and intestinal (blue arrow) and mesenteric vessels ligature (right panel).

Intestinal lesion region resection surgical procedure

Three, six or twenty-four hours after intestinal ischemia and obstruction, rats were re-anesthetized to subject to enterectomy for remove ischemic and obstructed intestinal segment, followed by a subsequent anastomosis end to end with polypropylene 6.0 (Figure 3). After surgery, animals were return to the vivarium, with free access to water and food, until the euthanasia.
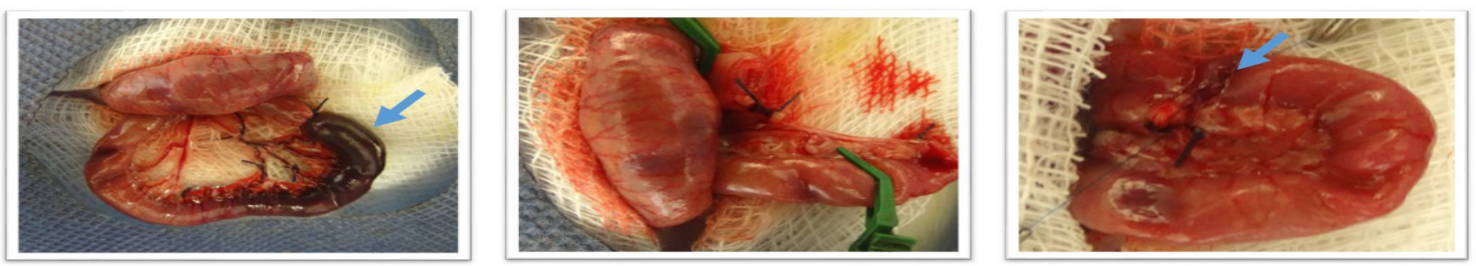

Figure 3 - Photography of rat small bowel showing ischemic lesion with necrosis (left panel - blue arrow), after lesion resection (central panel) and end to end anastomosis (right panel - blue arrow).

\section{Sample collection and euthanasia}

Under anesthesia, mesenteric lymph nodes, liver, spleen and lung tissues were surgically removed, according survival rate. Following, euthanasia was performed by exsanguination.

Bacterial translocation assessment

Each tissue sample homogenized in sterile $0.9 \%$ saline solution was used to evaluate 
bacterial Gram-negative colonies in Petri plate with MacConkey media (24 to 48 hours at $37 \circ \mathrm{C})$. Colonies were manually counted (colony forming unit - CFU) and normalized by tissue weight (g). Bacterial translocation was considered present when mesenteric lymph nodes were positive for Gram-negative and concomitantly other positive tissue (liver, spleen and/or lung). Intestinal ischemia and obstruction samples were compared to tissue from normal rat (Reference group, $n=5$ ).

\section{Statistical analysis}

The data were analyzed using the GraphPadPrism statistical program, version 5.01. Data was expressed as mean \pm SEM or median (interquartile range). Comparisons among groups were performed using One

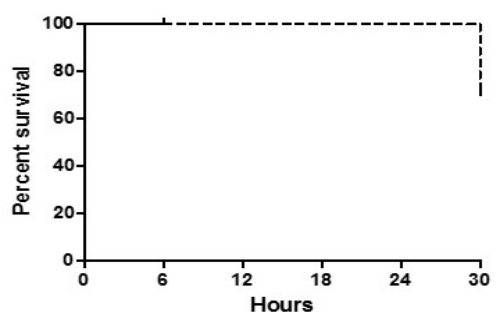

Way Anova or Kruskal-Wallis complemented by post-hoc test. Mortality was analyzed using long-rank test. A $P$-value $\leq 0.05$ was considered significant.

\section{- Results}

\section{Models survival rate}

All animals subjected to intestinal ischemia and obstruction for 3 hours survived 24 hours after enterectomy. However, on the $2^{\text {nd }}$ protocol, $6 \mathrm{~h} \times 24 \mathrm{~h}$, survival was $70 \%$ at 24 hours after enterectomy. On the $3^{\text {rd }}$ Protocol, $24 \mathrm{~h} \times 24 \mathrm{~h}$, survival was $70 \%$ and $40 \%, 24 \mathrm{~h}$ before and after enterectomy, respectively (Figure 4).

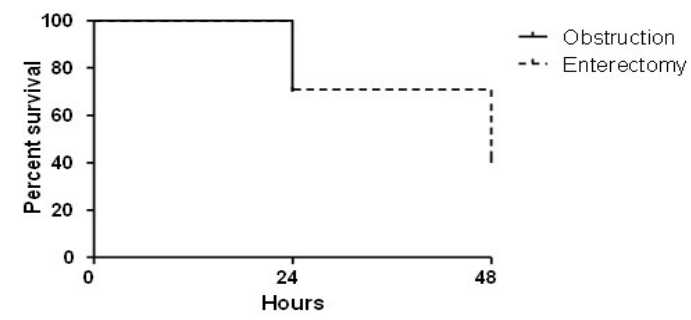

Figure 4 - Graphs depict survival rate of $2^{\text {nd }}$ protocol $(6 \times 24 h)$ of small bowel ischemia and obstruction model (left) and of $3^{\text {rd }}$ protocol $\left(24 \times 24 \mathrm{~h}\right.$, right). Note high level of mortality in $3^{\text {rd }}$ protocol, including that occurs during ischemia and obstruction and after enterectomy.

\section{Bacterial translocation assessment}

Culture of mesenteric lymph nodes and other tissues showed positivity on the $2^{\text {nd }}$
Protocol $(6 \mathrm{~h} \times 24 \mathrm{~h})$ and negativity on the $1^{\text {st }}(3 \mathrm{~h}$ $x$ 24h). Tissues from the $3^{\text {rd }}$ Protocol were not cultured because of high mortality rate (Table 1).

Table 1 - Bacterial translocation $24 \mathrm{~h}$ after enterectomy to remove intestinal lesion in all protocols of experimental model of intestinal ischemia and obstruction.

\begin{tabular}{lllll} 
& & \multicolumn{3}{l}{ Interval of intestinal ischemia and obstruction } \\
& Reference & $\mathbf{3 h}$ & $\mathbf{6 h}$ & $\mathbf{2 4 h}$ \\
\hline Bacterial Translocation & Absent & Absent & Present & NA \\
Mesenteric lymph nodes & 0 & 0 & $1613 \pm 501 \mathrm{CFU} / \mathrm{g}$ & $\mathrm{NA}$ \\
Spleen & 0 & 0 & $361 \pm 212 \mathrm{CFU} / \mathrm{g}$ & $\mathrm{NA}$ \\
Liver & 0 & 0 & $136 \pm 79 \mathrm{CFU} / \mathrm{g}$ & $\mathrm{NA}$ \\
Lungs & 0 & 0 & $916 \pm 612 \mathrm{CFU} / \mathrm{g}$ & $\mathrm{NA}$ \\
\hline
\end{tabular}

NA: not assessed. 


\section{- Discussion}

The experimental model of intestinal ischemia and obstruction was based on the simple bowel obstruction - ligature of terminal ileum, and ligature of blood vessels of this segment. Three distinct protocols were established according duration of intestinal ischemia and obstruction. It was calculated survival rate and assessed bacterial translocation in lymph nodes and other tissues.

The experimental model of intestinal obstruction in closed loop associated with ischemia previously described ${ }^{12}$ was the basis for the development of this model. The maintenance of the animals in a closedloop intestinal obstruction regimen added to ischemia for a 24-hour period, surely induced a systemic inflammatory response. Just threehours after enterectomy and fluid resuscitation animals underwent to euthanasia and this interval seemed to be short leaving a gap for more inflammatory changes.

Analyzing the model proposed by Zanoni et $a .^{13}$, the period of obstruction and ischemia was shown to be effective in inducing inflammatory response and bacterial translocation. Volume resuscitation was performed two hours after intestinal obstruction and ischemia; however, the enterectomy occurred only after 24 hours, which differentiates the model from clinical practice.

The experimental model we used is a simple bowel obstruction, in the terminal ileum approximately $1.5 \mathrm{~cm}$ from the cecum, without occlusion of the intestine proximally, and ligature of the blood vessels that irrigate the 7 to $10 \mathrm{~cm}$ of the distal small intestine.

The animals of the 3rd protocol had an overall mortality of $60 \%$, an expressive rate compared to the model of Zanoni et al. ${ }^{13}$, who had a mortality of less than $20 \%$ in animals submitted to non-replacement enterectomy.
The difference between these models consist in peritoneal lavage. This procedure should acts as hydration modifying survival rate in our model. Bacterial translocation to the tissues was not evaluated in these animals due to the high mortality, which made the model unfeasible, being attributed to a long period of ischemia and intestinal obstruction in small rodents.

Another study ${ }^{14}$ showed significant results, with animals being submitted to partial intestinal obstruction for a period of 12 hours, motivating the evaluation of animals submitted to ischemia and obstruction, undergoing enterectomy with anastomosis after 3 and 6 hours, euthanized 24 hours after resuscitation. The group that remained under strangulated intestinal obstruction and ischemia for 3 hours (1st protocol), followed by enterectomy with anastomosis, and euthanasia after 24 hours, did not present positive cultures at the moment of euthanasia. Unlike the 3rd protocol, the 3-hour period under intestinal obstruction and ischemia proved to be ineffective in promoting bacterial translocation, despite the absence of mortality, invalidating the model for this purpose.

Mortality in the group submitted to strangulated intestinal obstruction and ischemia for 6 hours and euthanasia 24 hours after enterectomy and anastomosis (2nd protocol) was absent until the time of the enterectomy, reaching $30 \%$ overall, an acceptable value in an experimental protocol. Cultures of mesenteric lymph nodes, spleen, liver and lungs were positive in this group, demonstrating their applicability in the evaluation of bacterial translocation in an experimental model of intestinal obstruction and ischemia.

Consistent models of intestinal obstruction as used by Sen et al. ${ }^{15}$ differ from this study because they produce ileal obstruction without ligature of the vessels, 
besides promoting euthanasia of the animals without performing enterectomy and anastomosis.

We consider in the model proposal the association of ischemia by ligature of the mesentery vessels, to simulate a clinical situation in which the factor that triggers the obstruction is usually associated, with pinching or torsion of vessels with consequent ischemia, as in hernias and peritoneal adhesion. In addition to the associated ischemia, the option of performing the enterectomy and anastomosis, contrary to most of the models, was used to reproduce the changes generated by reperfusion, as well as surgical morbidity and mortality, which reached $3.6 \%$ in an experimental model of the small intestine anastomosis ${ }^{16}$. Further studies should be done to establish inflammatory response as well.

\section{Conclusion}

The model that best approached the clinic was the one of $6 \times 24 \mathrm{~h}$ of ischemia and intestinal obstruction, in which it was observed bacterial translocation and low mortality rate.

\section{References}

1. Cappell MS, Batke M. Mechanical obstruction of the small bowel and colon. Med Clin North Am. 2008;92(3):575-97,viii. doi: 10.1016/j.mcna.2008.01.003.

2. Taylor MR, Lalani N. Adult small bowel obstruction. Acad Emerg Med. 2013;20(6):528-44. doi: 10.1111/ acem.12150.

3. Cruz Jr. RJ, Garrido AG, Ribeiro CM, Harada T, Rocha-e-Silva M. Regional blood flow distribution and oxygen metabolism during mesenteric ischemia and congestion. J Surg Res. 2010;161(1):54-61. doi: 10.1016/j. jss.2008.12.005.

4. Mulvihill SJ, Pappas TN, Fonkalsrud EW, Debas HT. The effect of somatostatin on experimental intestinal obstruction. Ann Surg. 1988;207(2):169-73. PMID: 1493368.
5. Aldemir M, Kökoglu OF, Geyik MF, Buyukbayram $H$. Effects of octreotide acetate and Saccharomyces boulardii on bacterial translocation in an experimental intestinal loop obstruction model of rats. Tohoku J Exp Med. 2002;198(1):1-9. PMID: 12498309.

6. El-Awady SI, El-Nagar M, El-Dakar M, Ragab M, Elnady G. Bacterial translocation in an experimental intestinal obstruction model. C-reactive protein reliability? Acta Cir Bras. 2009;24(2):98-106. PMID: 19377777.

7. Firat U, Senol S, Gelincik I, Kapan M, Tokgoz $\mathrm{O}$, Tekin R, Evliyaoglu O, Onder A, Alp H. The effects of caffeic acid phenethyl ester (CAPE) on bacterial translocation and inflammatory response in an experimental intestinal obstruction model in rats. Eur Rev Med Pharmacol Sci. 2015;19(10):1907-14. PMID: 26044239.

8. Akçay MN, Capan MY, Gündogdu C, Polat $M$, Oren D. Bacterial translocation in experimental intestinal obstruction. J Int Med Res. 1996;24(1):17-26. doi: 10.1177/030006059602400103.

9. Quirino IE, Cardoso VN, Santos Rd, Evangelista WP, Arantes RM, Fiúza JA, Glória MB, Alvarez-Leite JI, Batista MA, Correia MI. The role of $\mathrm{L}$-arginine and inducible nitric oxide synthase in intestinal permeability and bacterial translocation. JPEN J Parenter Enteral Nutr. 2013;37(3):392-400. doi: 10.1177/0148607112458325.

10.Zanoni FL1, Benabou S, Greco KV, Moreno AC, Cruz JW, Filgueira FP, Martinez MB, Figueiredo LF, Silva MR, Sannomiya $P$. Mesenteric microcirculatory dysfunctions and translocation of indigenous bacteria in a rat model of strangulated small bowel obstruction. Clinics. 2009;64(9):911-9. doi: 10.1590/S1807-59322009000900013.

11.Pujahari AK. Decision making in bowel obstruction: a review. J Clin Diagn Res. 2016;10(11):PE07-PE12. doi: 10.7860/ JCDR/2016/22170.8923.

12.Rasslan R, Utiyama EM, Marques GM, Ferreira TC, Costa VA, de Victo NC, Rasslan $S$, Montero EF. Inflammatory activity modulation by hypertonic saline and pentoxifylline in a rat model of strangulated closed loop small bowel obstruction. Int J Surg. 2014;12(6):594-600. doi: 10.1016/j. ijsu.2014.04.007. 
13.Luiz Zanoni F, Costa Cruz JW, Martins JO, Benabou S, Vicente Greco K, Ramos Moreno AC, Baquerizo Martinez M, Ferraro Calderaro F, Rocha e Silva M, Sannomiya P. Hypertonic saline solution reduces mesenteric microcirculatory dysfunctions and bacterial translocation in a rat model of strangulated small bowel obstruction. Shock. 2013;40(1):35-44. doi: 10.1097/ SHK.0b013e318299d3fa.

14.Yuan ML, Yang Z, Li YC, Shi LL, Guo JL, Huang YQ, Kang $X$, Cheng JJ, Chen Y, Yu T, Cao DQ, Pang $H$, Zhang $X$. Comparison of different methods of intestinal obstruction in a rat model. World J Gastroenterol.
2013;19(5):692-705. doi: 10.3748/wjg.v19. i5.692.

15.Şen V, Uluca Ü, Ece $A$, Güneş $A$, Zeytun $H$, Arslan S, Kaplan I, Türkçü G, Tekin R. Role of Ankaferd on bacterial translocation and inflammatory response in an experimental rat model of intestinal obstruction. Int J Clin Exp Med. 2014;7(9):2677-86. PMID: PMC4211775.

16. Marjanovic G1, Holzner P, Kulemann B, Kuesters $S$, Karcz WK, Timme $S$, Zur Hausen A, Baumann T, Hopt UT, Obermaier R, Hoeppner J. Pitfalls and technical aspects during the research of intestinal anastomotic healing in rats. Eur Surg Res. 2010;45(3-

\section{Correspondence:}

Edna Frasson de Souza Montero

Alameda Espada, 134 - Residencial Onze 06540-395 Santana de Parnaíba - SP Brasil

Received: Apr 03, 2017

Review: June 06, 2017

Accepted: July 08, 2017
Conflict of interest: none

Financial source: CNPq (Process number: 308995/2012-0)

${ }^{1}$ Research performed at Laboratory of Surgical Physiopathology - LIM-62, Department of Surgery, Faculdade de Medicina da Universidade de Sao Paulo (FMUSP), Brazil. Part of PhD degree thesis, Postgraduate Program in Surgical Clinics. Tutor: Edna Frasson de Souza Montero. 